\title{
Multi Quadrant Operation of Brushless Direct Current Motor Drive with PI and Fuzzy Logic Controllers
}

\author{
B.V. Arun Kumar \\ Research Scholar, Department of Electrical and Electronics Engineering, Sri Venkateswara University College \\ of Engineering, SV University, Tirupati, Andhrapradesh, India-517502. \\ Email: venkatarun206@gmail.com \\ Dr .G V Marutheswar \\ Professor, Department of Electrical and Electronics Engineering, Sri Venkateswara University College of Engineering, \\ SV University, Tirupati, Andhrapradesh, India-517502. \\ Email: marutheswargv@gmail.com
}

Received: 03 January 2019; Accepted: 20 February 2019; Published: 08 May 2019

\begin{abstract}
This paper presents that the simulation of control of three phase Brushless Direct Current (BLDC) motor in all four quadrants with PI and Fuzzy Logic controllers (FLC). Traditionally the speed control of motors is carried out by conventional motors with using $\mathrm{P}$, PI, PID and some other control techniques [5]. But it provides a chance to occurrence of nonlinearity \& uncertainties that causes some internal and external parameter errors. The efficient speed control in four quadrant operation can be achieved by using a fuzzy logic controller. The improvisation of Brushless Direct current motor drive through fuzzy logic controller in all four quadrants is done using simulink/MATLAB [7].
\end{abstract}

Index Terms-BLDC motor, Fuzzy Logic controller (FLC), Multi quadrant operation,FPGA

\section{INTRODUCTION}

In various industrial and home applications Brushless Direct Current motors are used in extent manner. Due to advantages of Brushless DC motors there is improved control schemes to predict the presentation of the motor. In a conventional brushed Direct Current motor, the brushes are accountable for making the mechanical contact with a set of electrical contacts on the rotor referred to as the commutator. This forms an electric circuit connecting the DC electrical source and the armature coil windings. While the armature rotates, the motionless brushes come in contact with dissimilar sections of the commutator. The rotating commutator and the brush system shape a set of electrical switches which operate in a series to allow electric current to flow through the armature coils nearby to the field which may be an electromagnet or a permanent magnet. In a Brushless Direct Current motor, armature coils do not move, and in its place the permanent magnets rotate. Therefore the armature remains stationary which avoids the difficulty of how to move current to a moving armature. In a Brushless Direct Current motor, the commutator assembly is replaced by an electronic controller which is programmed to perform the coil switching [1]. The major advantages of Brushless DC motor such as elevated efficiency, extended operating life, low down noise, and variable high speed ranges.

Brushless Direct Current motors come across applications in each section of the market such as appliances, industrial control, automation, aviation, etc. Brushless Direct Current motor operation control can be divided into three most important types such as constant load, varying loads and positioning applications. The BLDC motor consruction is shown below in Fig.1 

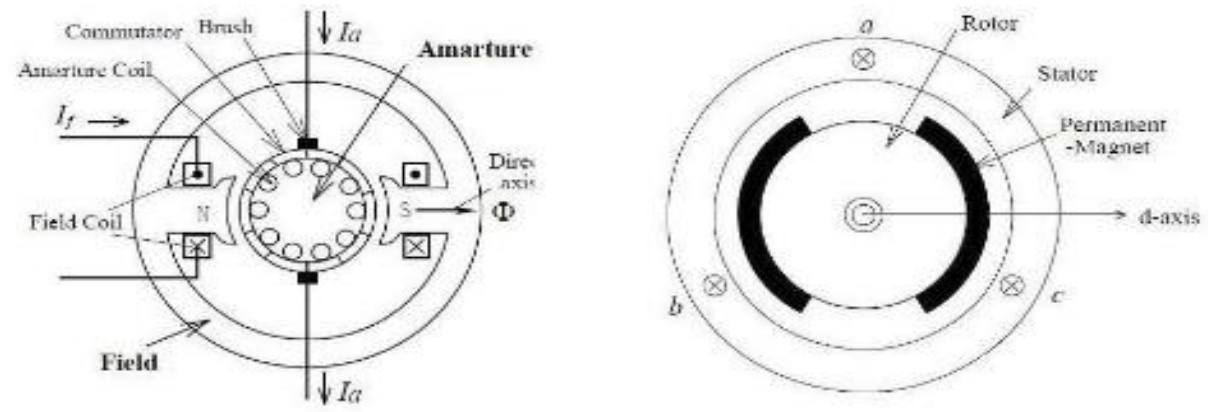

Fig. 1 BLDC Motor constructions

\section{Modeling Of The Brushless Direct CurRent (BLDC) MOTOR DRIVE SYSTEM:}

\section{A. Modeling of BLDC Motor}

abc phase changeable and $\mathrm{d}-\mathrm{q}$ axis models are used mathematically in BLDC motor. In a BLDC motor the back emf is trapezoidal in nature implies that non sinusoidal mutual inductance among stator and rotor windings, and then renewed in to $\mathrm{d}-\mathrm{q}$ axis representation. This method is not having a exacting advantage, so we go for adc phase variable technique. Here we assumed that BLDC motor is star linked through isolated neutral[2]. In BLDC motor modeling the subsequent assumptions are not drenched [4].

i. Self and Mutual inductances made i.e.

ii BLDC Motor is are invariable and stator resistance of all windings is like.

iii. Semiconductor devices are ideal in nature.

The balanced circuit of the BLDC servomotor drive scheme is shown. The line to line voltage equations in matrix equation (1) is given as

$$
\begin{gathered}
{\left[\begin{array}{c}
V_{a b} \\
V_{b c} \\
V_{c a}
\end{array}\right]=\left[\begin{array}{ccc}
R & -R & 0 \\
0 & R & -R \\
-R & 0 & -R
\end{array}\right]\left[\begin{array}{c}
i_{a} \\
i_{b} \\
i_{c}
\end{array}\right]+\left[\begin{array}{ccc}
L-M & M-L & 0 \\
0 & L-M & M-L \\
M-L & 0 & L-M
\end{array}\right]+} \\
\times \frac{d i}{d t}\left[\begin{array}{c}
i_{a} \\
i_{b} \\
i_{c}
\end{array}\right]+\left[\begin{array}{c}
e_{a}-e_{b} \\
e_{b}-e_{c} \\
e_{c}-e_{a}
\end{array}\right]
\end{gathered}
$$

Mutual inductance (M) is neglected as compared to the self-inductance (L); as a result matrix equation(2) can be rewritten as

$$
\begin{gathered}
{\left[\begin{array}{c}
V_{a b} \\
V_{b c} \\
V_{c a}
\end{array}\right]\left[\begin{array}{ccc}
R & -R & 0 \\
0 & R & -R \\
-R & 0 & -R
\end{array}\right]\left[\begin{array}{c}
i_{a} \\
i_{b} \\
i_{c}
\end{array}\right]+\left[\begin{array}{ccc}
L & -L & 0 \\
0 & L & -L \\
-L & 0 & L
\end{array}\right] \times \frac{d i}{d t}\left[\begin{array}{l}
i_{a} \\
i_{b} \\
i_{c}
\end{array}\right]+} \\
{\left[\begin{array}{l}
e_{a}-e_{b} \\
e_{b}-e_{c} \\
e_{c}-e_{a}
\end{array}\right]}
\end{gathered}
$$

Where

$\mathrm{L}=$ Self-inductance.

$\mathrm{M}=$ per phase Mutual inductance;

$\mathrm{R}=$ per phase stator winding Resistance;

$e_{a}, e_{b}$ and $e_{c}=$ phases a, b, and c Back EMFs; $i_{a}, i_{b}, i_{c}=$ phase streams of phases a, b, and c, individually.

In BLDC motor, torque generated by means of the BLDC motor can be expressed equation (3) as shown below

$$
\mathrm{T}_{\mathrm{e}}=\left(\mathrm{e}_{\mathrm{a}} \mathrm{i}_{\mathrm{a}}+\mathrm{e}_{\mathrm{b}} \mathrm{i}_{\mathrm{b}}+\mathrm{e}_{\mathrm{c}} \mathrm{i}_{\mathrm{c}}\right) / \omega=\mathrm{K}_{\mathrm{t}} \mathrm{I}
$$

Where $i_{a}=i_{b}=i_{c}=\mathrm{I}, \omega$ is the speed in $\mathrm{r} / \mathrm{s}$, and $K_{t}$ is the torque invariable. Since this torque generated by means of the BLDC motor is used to conquer the differing torques of inertia and load, it can also be written equation (4) as

$$
T_{e}=T_{L}+J_{M} d_{\omega} / d t+B_{M} \omega
$$

Where $\mathrm{T}_{\mathrm{L}}=$ load torque

$\mathrm{J}_{\mathrm{M}}=$ inertia, and $B_{M}=$ friction invariable of the BLDC servomotor. The load torque can be articulated in requisites of load inertia $\mathrm{J}_{\mathrm{L}}$ and friction $\mathrm{B}_{\mathrm{L}}$ mechanism in equation (5) as

$$
T_{L}=J_{L} \frac{d \omega}{d t}+B_{L} \omega
$$

The power output developed by BLDC motor is shown below equation (6) and (7) as

$$
\begin{gathered}
P=T_{e} \omega \\
E=e_{a}=e_{b}=e_{c}=K_{b} \omega
\end{gathered}
$$

Where $\mathrm{K}_{\mathrm{b}}$ is back Electro Motive Force constant, $E$ is back Electro Motive Force per phase and $\omega$ is the speed in $\mathrm{r} / \mathrm{s}$. It possibly will be observed that, the function shown in table I are 120 degree phase shifted.

\section{B. Modeling of Back Electro Motive Force (EMF) using Rotor Position}

The phase Back Electro Motive Force(EMF) in the Permanent Magnet Brushless Direct Current motor is trapezoidal waveform and is the function of the speed $\omega_{m}$ and position of rotor angle $\theta_{r}$ as shown in Fig 3.3.From this, the phase back Electro Motive Force's can be expressed as. 


$$
\left[\begin{array}{l}
e_{a} \\
e_{b} \\
e_{c}
\end{array}\right]=\omega_{m} \lambda_{m}\left[\begin{array}{l}
f_{a s}\left(\theta_{r}\right) \\
f_{b s}\left(\theta_{r}\right) \\
f_{c s}\left(\theta_{r}\right)
\end{array}\right]
$$

Where $f_{a s}\left(\theta_{r}\right), f_{b s}\left(\theta_{r}\right), f_{c s}\left(\theta_{r}\right)$ are unit function producer to analogous to the trapezoidal induced emfs of the BLDCM as a function of $\theta_{r}$. The $f_{b s}\left(\theta_{r}\right), f_{c s}\left(\theta_{r}\right)$ are similar to $f_{a s}\left(\theta_{r}\right)$ but phase displacement of 120 degrees.

$$
\mathrm{f}_{\mathrm{as}}\left(\theta_{\mathrm{r}}\right)=\left\{\begin{array}{cc}
\theta_{\mathrm{r}} \frac{6}{\pi} & , 0 \leq \theta_{\mathrm{r}}<\frac{\pi}{6} \\
1 & , \frac{\pi}{6} \leq \theta_{\mathrm{r}}<\frac{5 \pi}{6} \\
\left(\pi-\theta_{\mathrm{r}}\right) \frac{6}{\pi} & , \frac{5 \pi}{6} \leq \theta_{\mathrm{r}}<\frac{7 \pi}{6} \\
-1 & , \frac{7 \pi}{6} \leq \theta_{\mathrm{r}}<\frac{11 \pi}{6} \\
\left(\theta_{\mathrm{r}}-2 \pi\right) \frac{6}{\pi} & , \frac{11 \pi}{6} \leq \theta_{\mathrm{r}}<2 \pi
\end{array}\right.
$$

Accordingly $\mathrm{f}_{\mathrm{bs}}\left(\theta_{\mathrm{r}}\right)$ and $\mathrm{f}_{\mathrm{cs}}\left(\theta_{\mathrm{r}}\right)$ can be designed.

The modeling of the brushless direct current motor includes the reliasation as a function of rotor electrical angle with hall sensors which can be scheduled in below table I.

\begin{tabular}{|c|c|}
\hline Theta_elec & $\mathbf{h}_{\mathrm{a}} \mathbf{h}_{\mathrm{b}} \mathbf{h}_{\mathbf{c}}$ \\
\hline $0^{0}-60^{0}$ & $\begin{array}{lll}1 & 0 & 1\end{array}$ \\
\hline $60^{\circ}-120^{\circ}$ & $\begin{array}{|lll|}0 & 0 & 1\end{array}$ \\
\hline $120^{\circ}-180^{\circ}$ & $\begin{array}{lll}0 & 1 & 1\end{array}$ \\
\hline $180^{\circ}-240^{\circ}$ & $\begin{array}{lll}0 & 1 & 0\end{array}$ \\
\hline $240^{\circ}-300^{\circ}$ & $\begin{array}{lll}1 & 1 & 0\end{array}$ \\
\hline $300^{\circ}-360^{\circ}$ & $\begin{array}{lll}1 & 0 & 0\end{array}$ \\
\hline
\end{tabular}

Table 1. Hall sensors modeled as a function of rotor angle

\section{HySTERESIS CURRENT CONTROLLER (HCC)}

The Hysteresis current controller serves to the production of the switching signals for the inverter. hysteresis-band Pulse Width Modulation is on the whole an immediate feedback control of current in Pulse Width Modulation(PWM) where the actual current repeatedly tracks the domination current within hyssteresisband.Fig.3.2 explains the operation principle of hysteresis-band Pulse Width Modulation(PWM) for half controlled bridge inverter. The control circuit produces the sine position current and it's compared with real phase current wave. The current go beyond upper band limit the upper switch is off and lower switch is on. As the current go beyond lower band boundary upper switch is on and lower switch is off like this control of the other phase going on.

The switching logic is formulated as given below.

$$
\begin{array}{ll}
\text { If } \mathrm{i}_{\mathrm{a}}<\left(\mathrm{i}_{\mathrm{a}}^{*}-\mathrm{h}_{\mathrm{b}}\right) & \mathrm{S} 1 \text { ON and S4 OFF } S_{A}=1 \\
\text { If } \mathrm{i}_{\mathrm{a}}<\left(\mathrm{i}_{\mathrm{a}}^{*}+\mathrm{h}_{\mathrm{b}}\right) & \mathrm{S} 1 \text { OFF and S 4 ON } S_{A}=0 \\
\text { If } \mathrm{i}_{\mathrm{b}}<\left(\mathrm{i}_{\mathrm{b}}^{*}-\mathrm{h}_{\mathrm{b}}\right) & \text { S 3 ON and S 6 OFF } S_{B}=1
\end{array}
$$

$$
\begin{array}{ll}
\text { If } \mathrm{i}_{\mathrm{b}}<\left(\mathrm{i}_{\mathrm{b}}^{*}+\mathrm{h}_{\mathrm{b}}\right) & \mathrm{S} 3 \text { OFF and S 6 ON } S_{B}=0 \\
\text { If } \mathrm{i}_{\mathrm{c}}<\left(\mathrm{i}_{\mathrm{c}}^{*}-\mathrm{h}_{\mathrm{b}}\right) & \mathrm{S} 5 \text { ON and S 2 OFF } S_{C}=1 \\
\text { If } \mathrm{i}_{\mathrm{c}}<\left(\mathrm{i}_{\mathrm{c}}^{*}-\mathrm{h}_{\mathrm{b}}\right) & \mathrm{S} 5 \text { OFF and S 2 ON } S_{C}=0
\end{array}
$$

Where, $h_{b}$ is the hysteresis band approximately the three phase's position currents, according to above switching state of the inverter output voltage equations (10),(11),(12) are given below

$$
\begin{aligned}
& v_{a}=\frac{1}{3}\left[2 S_{A}-S_{B}-S_{C}\right] \\
& v_{b}=\frac{1}{3}\left[-S_{A}+2 S_{B}-S_{C}\right] \\
& v_{c}=\frac{1}{3}\left[-S_{A}-S_{B}+2 S_{C}\right]
\end{aligned}
$$

\section{INVERTER CONTROL}

Fig. 2 shows a basic block diagram of Brushless Direct Current Motor (BLDCM) control performance for a three phase motor. The circuit uses six power transistors, Metal Oxide Field Effect Transistors or IGBTs. The switches are controlled consequently to provide suitable commutation to the windings in synchronism by means of rotor dislocation, given that the function of the commutator.

In Brushless Direct Current Motor, two phases conduct at a time and the third one drifts and each phase conducts for $120^{\circ}$ electrical degrees. The commutation moment occurs when the rotor near by a position reflecting $30^{\circ}$ electrical. From that position, one conducting phase is chopped out and the floating phase starts conducting current and so on at an additional position of the rotor subsequent to $120^{\circ}$ electrical to maximize torque, progress the efficiency and lower the torque ripple

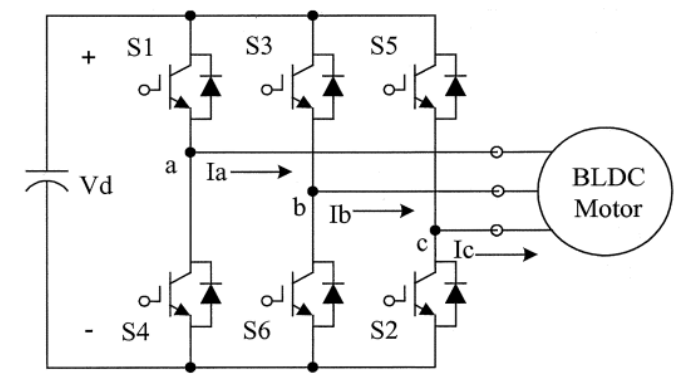

Fig.2. VSI fed BLDC Motor Drive

\section{Pi CONTROLler}

The PMBLDCM drive having a speed controller, position current generator, Pulse Width Modulation current controller, position sensor, the motor and IGBT based voltage source inverter with current controlled condition. The motor speed is matched with its position value and the speed error is processed with PI speed controller. 


$$
\mathrm{e}(\mathrm{t})=\mathrm{w}_{\mathrm{ref}}-\mathrm{w}_{\mathrm{m}}(\mathrm{t})
$$

Where $\mathrm{w}_{\mathrm{m}}(\mathrm{t})$ is matched with the reference speed $\omega_{\text {ref }}$ and the output error is estimated at the nth sampling instant is shown in equation (14) as.

$$
\mathrm{T}_{\mathrm{ref}}=\mathrm{T}_{\mathrm{ref}}(\mathrm{t}-1)+\mathrm{K}_{\mathrm{p}}[\mathrm{e}(\mathrm{t})-\mathrm{e}(\mathrm{t}-1)]+\mathrm{K}_{\mathrm{i}} \mathrm{e}(\mathrm{t})
$$

Where $\mathrm{K}_{\mathrm{p}}$ and $\mathrm{Ki}_{\mathrm{i}}$ are the gains of PI speed controller[8].
The output of the controller is considered as the reference torque. A boundary is put on the speed controller output depending on the allowable highest winding currents. The position current producer block produces the three phase position currents ia, ib, ic using the some degree of peak currents magnitude decided by the controller and the position sensor. The simulink block diagram representation of Brushless Direct Current Motor with PI Controller Shows in below Fig.3

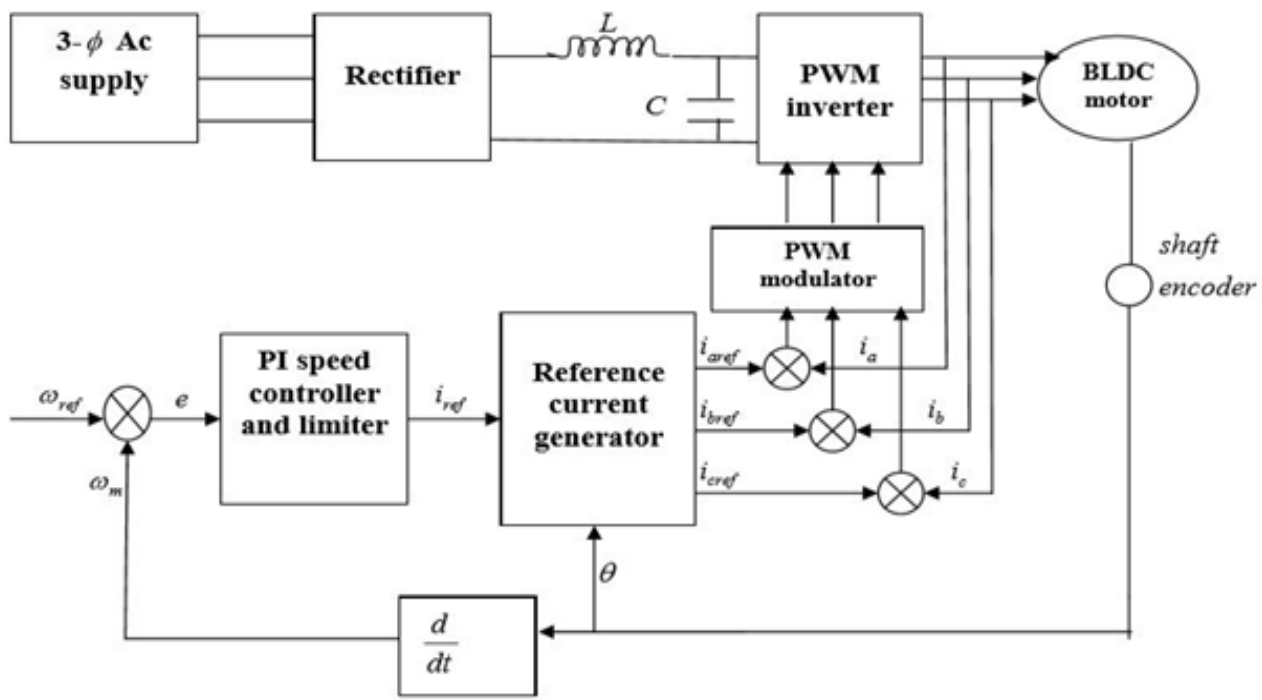

Fig.3. simulink block diagram representation of Brushless Direct Current Motor with PI Controller

\section{FuZZY LOGIC CONTROLLER (FLC)}

The controller with fuzzy logic was applied to the speed controller by replacing the PI controller. The fuzzy logic controlled Brushless Direct Current Motor drive system block diagram is shown in Fig.4

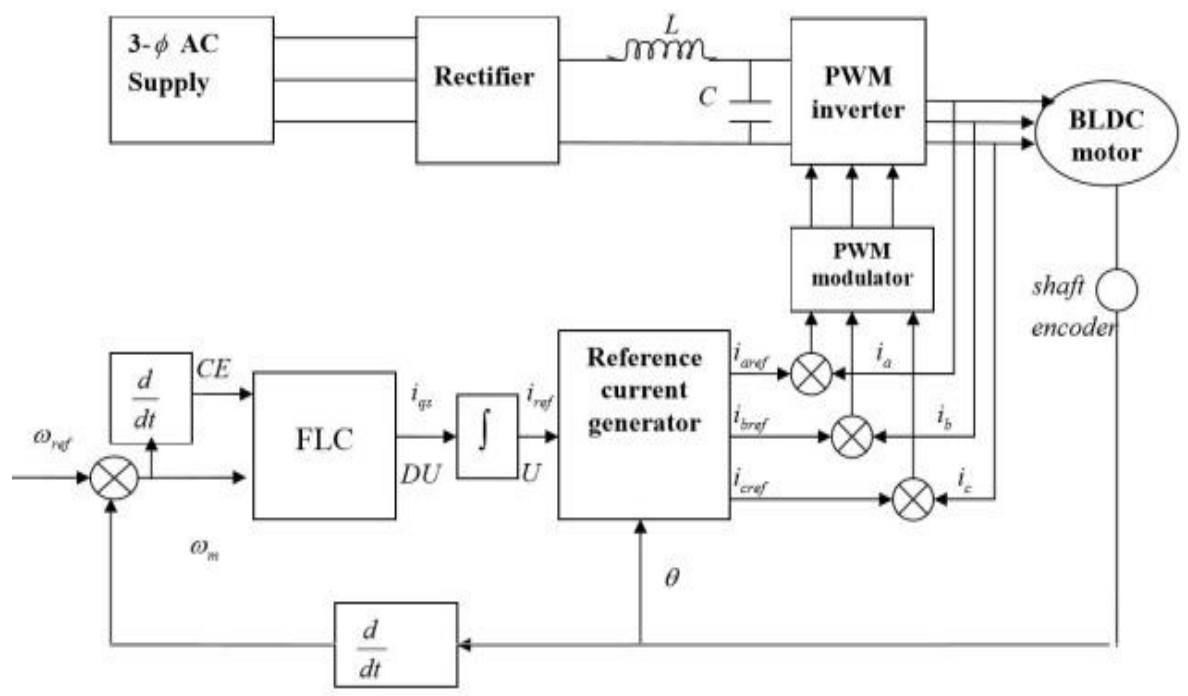

Fig.4. simulink block diagram representation of Brushless Direct Current Motor with FLC

The controller is calculated the input variable such as speed error(E) and change in error in speed(CE).The output variable is known as position or reference current Iref which is a component of torque and is obtained by using the change in position current at output of controller. The pattern of error signal is observed by controller and corresponding otput DU so that the real speed compared with the reference speed Wref.the FLC is havinf the two input signals, first one is the error $\mathrm{E}=$ $\omega_{\text {ref }}-\omega_{m}$ and second one is the change in error CE, which is connected to the derivative $\frac{d E}{d t}=\frac{\Delta E}{\Delta t}=\frac{C E}{T_{S}}$, 
where $\Delta E$ in the sampling time $T_{s}, \mathrm{CE}$ is preportional to $\frac{d E}{d t}$. The output of the controller DE in brushles direct current motor drive is $\Delta \mathrm{i}_{\mathrm{qs}}^{*}$ current. The signal is incorporated to generate the real control signal $U$ or current $\mathrm{i}_{\mathrm{qs}}^{*}$. We can write those equations (15),(16) as

$$
\begin{aligned}
\int \mathrm{DU} & =\int \mathrm{K}_{1} \mathrm{Edt}+\int \mathrm{K}_{2} \mathrm{CEdt} \\
\mathrm{U} & =\mathrm{K}_{1} \int \mathrm{Edt}+\mathrm{K}_{2} \mathrm{E}
\end{aligned}
$$

where $K_{1}$ and $K_{2}$ are gain factors together with the summation process.

The adaptive gains with non linear charecteristics in extending the same principle we can write a FLC algorithm for $\mathrm{P}$ and P-I-D. The fuzzy membership functions for the input variable and output variable are selected as follows:

Positive Large: PL Negative Large: NLPositive Medium: PM Negative Medium: NM Positive Small: PS Negative Small: NS And zero: ZO

The speed error (E) and change in error (CE) is distinct in the ranges are shown equqtion (17) and (18) below

$$
-1 \leq \omega_{\mathrm{e}} \leq+1
$$

and

$$
-1 \leq \omega_{\text {ce }} \leq+1
$$

and the output variable reference current change $\Delta \mathrm{i}_{\mathrm{qs}}$ is define in the range equation (19) is shown below

$$
-1 \leq \Delta \mathrm{i}_{\mathrm{qs}} \leq+1
$$

The member ship functios are taken as traingular shpae due that resulting most excellent control performance and effortlessness. The membership function for the error and the change in error and the change in torque reference current are shown in Fig.5, Fig.6, and Fig.7 respectively. For all variables seven levels of fuzzy membership function are used Table. II show the rule base table that was used in the system.

\section{A. Rule base Table:}

The following Table 2 represents the Rules for fuzzy lolgic control

Table 2. Rule base table

\begin{tabular}{|l|l|l|l|l|l|l|l|}
\hline e/ce & NL & NM & NS & ZO & PS & PS & PL \\
\hline NL & NL & NL & NL & NL & NM & NS & ZO \\
\hline NM & NL & NL & NL & NM & NS & ZO & PS \\
\hline NS & NL & NL & NM & NS & ZO & PS & PM \\
\hline ZO & NL & NM & NS & ZO & PS & PM & PL \\
\hline PS & NM & NS & ZO & PS & PM & PL & PL \\
\hline PM & NS & ZO & PS & PM & PL & PL & PL \\
\hline PL & ZO & PS & PM & PL & PL & PL & PL \\
\hline
\end{tabular}

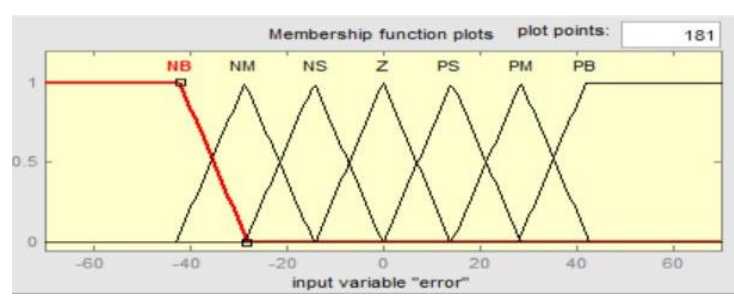

Fig.5. The speed error(E) Fuzzy membership function

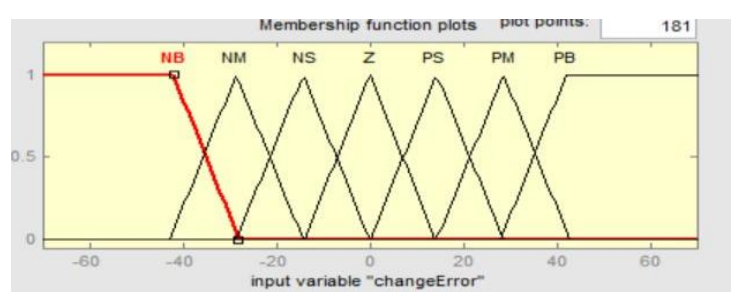

Fig.6. The change in error(CE) Fuzzy membershipfunction

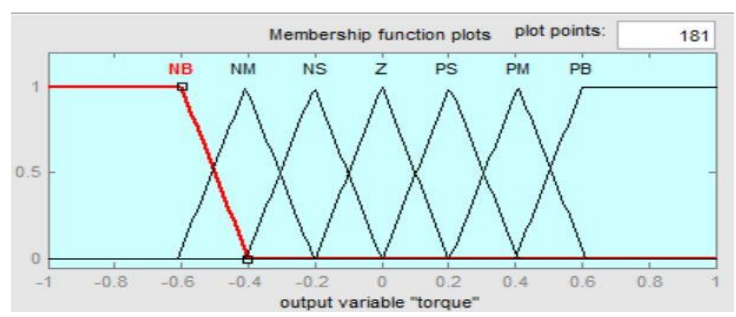

Fig.7.Change in torque Fuzzy member ship function

\section{RESUlTS AND DisCUSSION}

\section{A. PI Controller}

Here we obtain the simulation results of Brushless direct current motor drive with PI controller. Fig.8represents speed variation four qudrant operation with small over shoot[8].

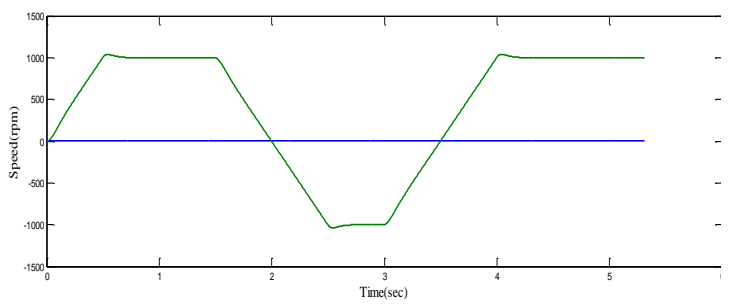

Fig.8. speed vs. time

Fig.9 represents the battery characteristics and the energy stored in regenerative braking mode [12] of BLDC motor with PI controller.

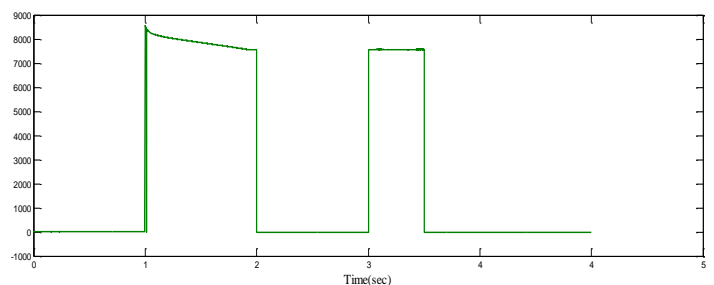




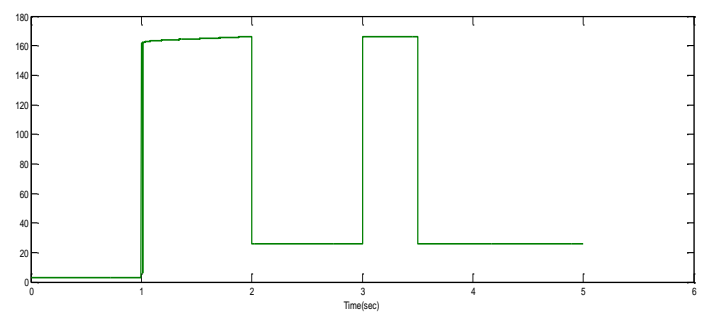

Fig.9. Battery charecteristics

The stator current ia is having more magnitude in motoring mode and reduced to low value in braking mode. Fig.10 represents the stator current in four quadrant mode

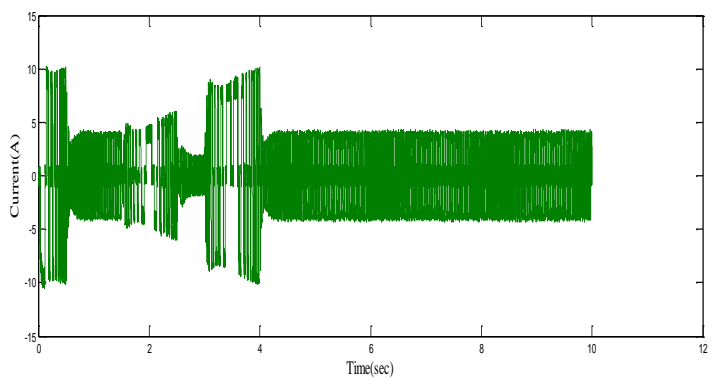

Fig.10. Stator current $i_{a}$

The variation in the amplitude of the stator back EMFs in one of all the three phases are clearly visible in the scope results shown in Fig.11 The trapezoidal shape is also seen.

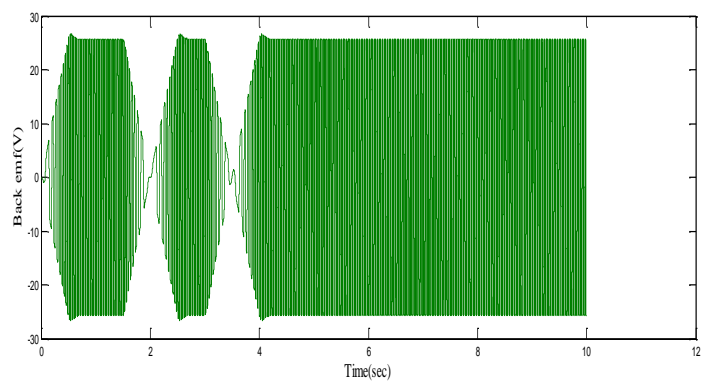

Fig.11. Back emf wave form $\mathrm{e}_{\mathrm{a}}$

\section{B. Quadrant determination}

Table 3. Quadrant determination

\begin{tabular}{|l|l|l|l|l|l|l|l|l|}
\hline Time & 0 & 0.8 & 1.0 & 1.5 & $\begin{array}{l}2 . \\
0\end{array}$ & $\begin{array}{l}2.6 \\
5\end{array}$ & $\begin{array}{l}2.7 \\
5\end{array}$ & $\begin{array}{l}3 . \\
0\end{array}$ \\
\hline $\begin{array}{l}\text { Refere } \\
\text { nce } \\
\text { speed }\end{array}$ & 0 & $\begin{array}{l}100 \\
0\end{array}$ & $\begin{array}{l}100 \\
0\end{array}$ & $\begin{array}{l}100 \\
0\end{array}$ & 0 & - & - & 0 \\
100 & $\begin{array}{l}100 \\
0\end{array}$ & \\
\hline $\begin{array}{l}\text { Applie } \\
\text { d } \\
\text { torque }\end{array}$ & 0 & 0 & +1 & -1 & -1 & -1 & +1 & 0 \\
\hline $\begin{array}{l}\text { Quadr } \\
\text { ant }\end{array}$ & $\begin{array}{l}\text { Initia } \\
1\end{array}$ & I & I & II & II & III & IV & - \\
\hline
\end{tabular}

The following table (III) represents that quadrant determination for given applied torque and speed

1. From start up to $0.8 \mathrm{~s}$, the torque applied is positive. That is, the motor is operation in the first quadrant, forward motoring.

2. At time $1.5 \mathrm{~s}$ negative torques is applied. This implies that a sudden brake is applied. The rotor speed is drastically brought to zero at $2.0 \mathrm{~s}$; this is the second quadrant of operation, forward braking.

3. At $2.65 \mathrm{~s}$ the motor is forced to rotate in the reverse direction, the applied torque remains negative. Since torque and speed are negative, the motor is in commission in the third quadrant, reverse motoring.

4. While at $2.75 \mathrm{~s}$ the load torque applied is positive, this is reverse motoring and sudden brake is applied which drops [9] down the rotor speed to zero rpm, indicating that the motor is in the fourth quadrant, reverse braking, of speed torque characteristics.

Here the below table IV represents that peak time, rise time, settling time and over shoot in case of forward and reverse motoring modes.

Table 4. Time calculation in forward motoring and reverse motoring modes respectively.

\begin{tabular}{|l|l|l|l|l|}
\hline Quadrant & $\begin{array}{l}\text { Peak } \\
\text { time }\end{array}$ & $\begin{array}{l}\text { Rise } \\
\text { time } \\
\text { (tr) }\end{array}$ & $\begin{array}{l}\text { Settling } \\
\text { time (ts) }\end{array}$ & $\begin{array}{l}\text { Over } \\
\text { shoot }\end{array}$ \\
\hline $\begin{array}{l}\text { Forward } \\
\text { motoring(I) }\end{array}$ & 0.55 & 0.45 & 0.65 & 0.04 \\
\hline $\begin{array}{l}\text { Reverse } \\
\text { motoring(III) }\end{array}$ & 2.55 & 0.45 & 2.65 & 0.04 \\
\hline
\end{tabular}

\section{Fuzzy Logic Controller}

Here we obtain the simulation results of Brushless direct current motor drive with PI controller.Fig. 12 represents speed variation four qudrant operation with zero over shoot.

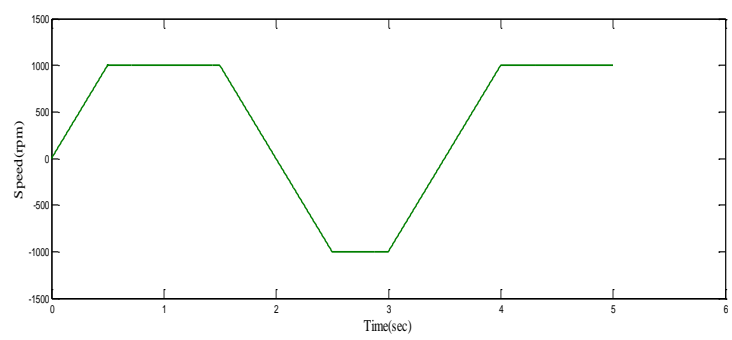

Fig.12. speed vs. time

The variation in the amplitude of the stator back EMFs in one of all the three phases with Fuzzy Logic controller are clearly visible in the scope results shown in Fig.13. The trapezoidal shape is also seen. The trapezoidal what we obtain will be more efficient than compared with PI controller. 


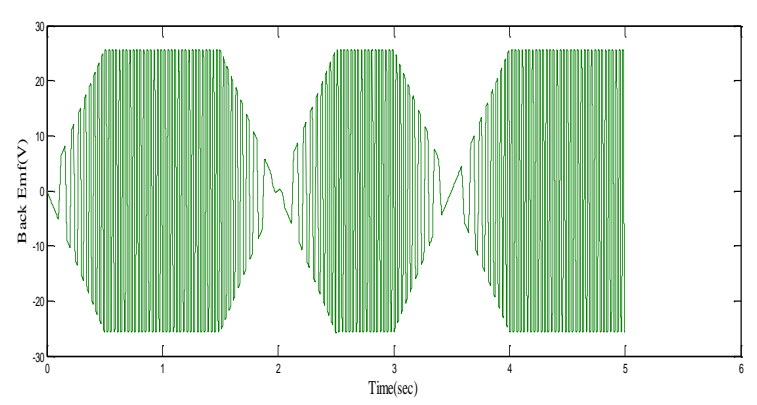

Fig.13. Back emf waveform $\mathrm{e}_{\mathrm{a}}$.

The stator current $i_{a}$ is having more magnitude in motoring mode and reduced to low value in braking mode. Fig.14represents the stator current in four quadrant mode

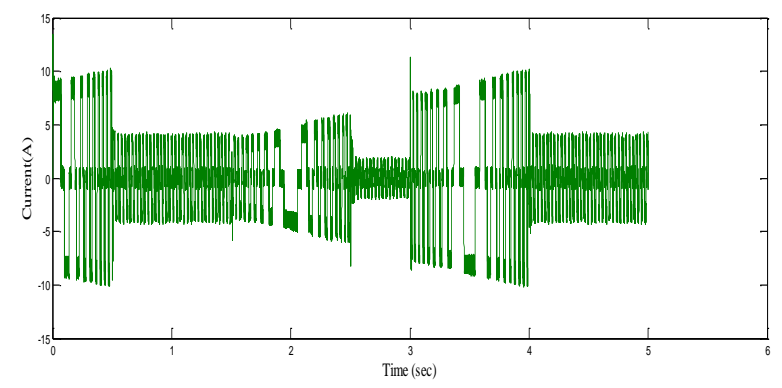

Fig.14. The stator currents of the three phases
Fig.15 represents the battery characteristics $[10,11]$ of Brushless direct current motor motor with FLC
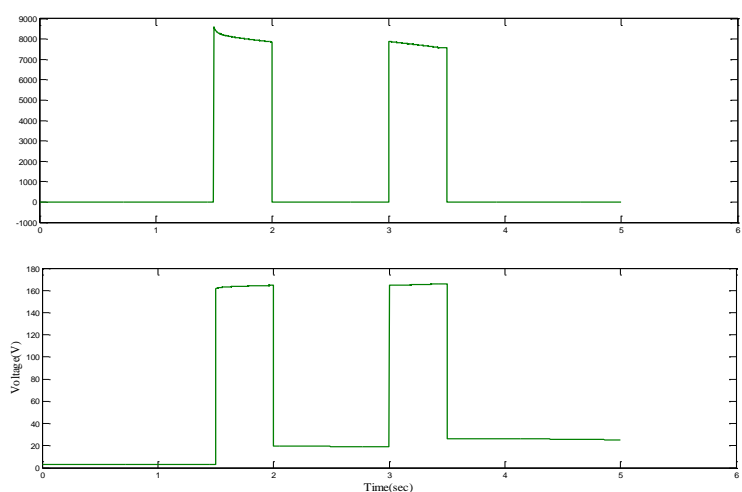

Fig.15. Battery Charecteristics

\section{Quadrant determination}

The following table (III) represents that quadrant determination for given applied torque and speed.

1. From start up to $1.0 \mathrm{~s}$, the torque applied is positive. That is, the machine is operation in the first quadrant, forward motoring.

2. At time $1.75 \mathrm{~s}$ negative torques is applied. This implies that a sudden brake is applied. The rotor speed is drastically brought to zero at $2.0 \mathrm{~s}$; this is the second quadrant of operation, forward braking.

Table 5. Quadrant determination

\begin{tabular}{|c|c|c|c|c|c|c|c|c|}
\hline Time & 0 & 0.5 & 1.0 & 1.5 & 2.0 & 2.50 & 2.75 & 3.0 \\
\hline $\begin{array}{c}\text { Reference } \\
\text { speed }\end{array}$ & 0 & 1000 & 1000 & 1000 & 0 & -1000 & -1000 & 0 \\
\hline $\begin{array}{c}\text { Applied } \\
\text { torque }\end{array}$ & 0 & 0 & +1 & -1 & -1 & -1 & +1 & 0 \\
\hline Quadrant & Initial & I & I & II & II & III & IV & - \\
\hline
\end{tabular}

3. At $2.5 \mathrm{~s}$ the motor is forced to rotate in the reverse direction, the applied torque remains negative. Since torque and speed are negative, the motor is operating in the III quadrant, reverse motoring.

4.While at $2.75 \mathrm{~s}$ the load torque applied is positive, this is reverse motoring and sudden brake is applied which drops down the rotor speed to zero rpm, indicating that the motor is in the fourth quadrant, reverse braking, of speed torque characteristics.

Here the below table VI represents that peak time, rise time, settling time and over shoot in case of forward and reverse motoring modes.

Table 6. Time calculation in forward motoring and reverse motoring modes respectively

\begin{tabular}{|l|l|l|l|l|}
\hline Quadrant & $\begin{array}{l}\text { Peak } \\
\text { time }\end{array}$ & $\begin{array}{l}\text { Rise } \\
\text { time } \\
(\mathrm{tr})\end{array}$ & $\begin{array}{l}\text { Settling } \\
\text { time (ts) }\end{array}$ & $\begin{array}{l}\text { Over } \\
\text { shoot }(\%)\end{array}$ \\
\hline $\begin{array}{l}\text { Forward } \\
\text { motoring(I) }\end{array}$ & 0.5 & 0.40 & 0.50 & 0.0 \\
\hline $\begin{array}{l}\text { Reverse } \\
\text { motoring(III) }\end{array}$ & 2.5 & 0.40 & 2.50 & 0.0 \\
\hline
\end{tabular}

From above discussion we can say that the BLDC motor drive using fuzzy logic controller give zero percent of overshoot compare to conventional or PI controller both in forward and reverse motoring modes respectively.

\section{CONCLUSION}

The speed control of three phase BLDC motor drive in four or multi quadrant operation with PI and Fuzzy logic controllers can be achieved through simulink/matlab. The control of BLDC motor drive with PI control gives nonlinearity \& uncertainties that causes some internal and external parameter errors compared to FLC. The improvisation of BLDC motor drive with FLC in all four quadrants gives the efficient speed control i.e without over shoot and back emf could be pure trapezoidal compared with PI controller. 


\section{REFERNCES}

[1] R.Krishnan and A. J. Beutler, "Performance and design of an axial field permanent magnet synchronous motor servo drive," in Proc. IAS Annu. Meeting, pp. 634-640, 1985.

[2] Sim power Systems for use with Simulink, useres guide, Math Works Inc., Natick, MA, 2002. Math Works, 2001, Introduction to MATLAB, the Math Works, Inc. 6. T.J.E. Miller, "Brushless Permanent Magnet \& Reluctance Motor Drives" Clarendon Press, Oxford, Vol.2, pp: 192199, 1989

[3] Zhen-Yu Zhao. 1993. Masayoshi Tomizuka and Satoru Isaka Fuzzy Gain Scheduling of PID controllers. IEEE transactions on systems, man and cybernetics. 23(5).

[4] P. Pillay and R. krishnan. 2002. Modelling simulation and analysis of a Permanent magnet brushless Dc motor drive. IEEE trans. Ind Applicant. 26: 124-129.

[5] Chung-Wen Hung, Jen-Ta Su, Chih-Wen Liu, ChengTsung Lin and Jhih-Han Chen. 2010. Fuzzy Gain Scheduling PI controller for Sensorless four switches three phase BLDC motor. IEEE 978-1-4244-47831/10.

[6] Ji Hun, Li Zhiyong. 2008. Simulation of Sensorless Permanent magnetic brushless DC motor control System. Proceedings of the IEEE International conference on automation and logistics. September, Quigdao, China.

[7] N. J. Patil, R. H. Chile and L. M. Waghmare. 2010. Fuzzy Adaptive Controllers for Speed Control of PMSM Drive. International Journal of Computer Applications (0975 8887). 1(11).

[8] George K. I. Mann, Bao-Gang $\mathrm{Hu}$ and Raymond G. Gosine. 1999. Analysis of Direct Action Fuzzy PID Controller Structures. IEEE transactions on systems, man, and cybernetics-part b: cybernetics. 29(3).

[9] C.Hua and S.J.Kao,"Design and implementation ofregenerativebrakingsystemforelectricbicyclesbasedonD SP,'”inProc.6thIEEEConf.IndustrialElectron.pplications, $B$ eijing,2011,pp.703-707.

[10] W. Cui, H. Zhang, Y.-L. Ma, and Y.-J. Zhang, "Regenerative braking control method and optimal scheme for electric motorcycle," in Proc. Int. Conf. Power Engineering, Energy and Electrical Drives, Spain, 2011, pp. 1-6.
[11] J. Li, H. Zhang, Q. Wan, J. Liu, and H. Zhang, "A novel charging control for flywheel energy storage system based on BLDC motor," in Proc. Asia Paci fic Power and Energy Engineering Conference (APPEEC), China, Mar. 2010, pp. 1-3.

[12] M. K. Yoong, Y. H. Gan, G. D. Gan, C. K. Leong, Z. Y. Phuan, B. K. Cheah, and K. W. Chew, "Studies of regenerative braking in electricvehicle,"inProc.IEEEConf.SustainableUtilizationD evelopment Eng. Technol., Malaysia, Nov. 2010, pp. 4045.

\section{Authors' Profiles}

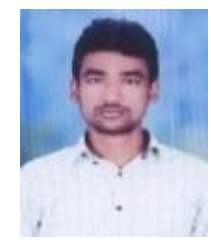

B.V. Arun Kumar received B.tech in Electrical and Electronics Engineering from RGMCET, Nandyal, M.Tech (power electronics) Degree in G. Pulla reddy Engineering College, Kurnool, presently Research Scholar in Department of Electrical and Electronics Engineering, Sri Venkateswara University College of Engineering, SV University, Tirupati, Andhrapradesh, India-517502. Email: venkatarun206@gmail.com

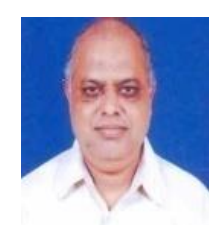

Dr .G V Marutheswar received B.tech, M.tech (Instrumenation and control engineering) \& Ph.D Degree in Electrical and Electronics Engineering from, S V University College of Engineering, S V University, Tirupati. Presently working as a Professor in Department of EEE Dept, S V University College of Engineering, SV University, Tirupati, Andhrapradesh, India-517502.

How to cite this paper: B.V. Arun Kumar, G V Marutheswar, "Multi Quadrant Operation of Brushless Direct Current Motor Drive with PI and Fuzzy Logic Controllers", International Journal of Information Engineering and Electronic Business(IJIEEB), Vol.11, No.3, pp. 25-32, 2019. DOI: 10.5815/ijieeb.2019.03.04 